\title{
Estudio constructivo de las ruinas de San Miguel de Sacramenia, como base para su restauración
}

\section{Constructive study of the ruins of San Miguel of Sacramenia, as base for its restoration}

M. Martínez-Monedero $^{(*)}$

RESUMEN

El artículo aborda el preocupante estado constructivo de las evocadoras ruinas de la Ermita de San Miguel de Sacramenia. Edificio que, a pesar de reunir importantes valores histórico, artístico y paisajístico, no ha recibido atención alguna en las últimas décadas y envejece anónimo con riesgo evidente de colapso. El texto aborda el estudio constructivo-patológico de sus ruinas como herramienta para informar de su precario estado y como base documental sobre la que fundamentar un posible proyecto de restauración que tenga como consecuencia su conservación.

Palabras clave: Estudio constructivo; ruinas; conservación; restauración; Ermita San Miguel; Sacramenia.

\section{ABSTRACT}

The paper discusses the constructive state of the evocative ruins of the Hermitage of San Miguel of Sacramenia. The building, despite gather important historical, artistic and landscape values, has not received some attention in recent decades and aging anonymous with obvious risk of collapse. The text addresses the constructive-pathological study of the ruins as a tool to denounce their precarious state and as documentation on which to base a possible restoration project that result in conservation.

Keywords: Constructive study; ruins; conservation; restoration; Hermitage of San Miguel; Sacramenia.

(*) ETS de Arquitectura - Universidad de Granada (España)

Persona de contacto/Corresponding author: miguel@mm-arquitectura.com (M. Martínez-Monedero).

Cómo citar este artículo/Citation: Martínez-Monedero, M. (2015). Estudio constructivo de las ruinas de San Miguel de Sacramenia, como base para su restauración. Informes de la Construcción, 67(539): eo99, doi: http://dx.doi.org/10.3989/ic.14.074.

Licencia / License: Salvo indicación contraria, todos los contenidos de la edición electrónica de Informes de la Construcción se distribuyen bajo una licencia de uso y distribución Creative Commons Reconocimiento no Comercial 3.o. España (cc-by-nc). 


\section{INTRODUCCIÓN}

Las ruinas de la Ermita de San Miguel son de los numerosos vestigios románicos que decoran el paisaje del páramo castellano. Sin un uso determinado, envejecen anónimos a la espera de que cualquier entidad, pública o privada, tenga a bien dedicar cierta atención para su conservación. Interés no les falta, pues, sin excepción, estos restos suelen enclavarse en lugares privilegiados, dominando un paisaje y siendo una importante referencia de una población cercana. En el caso que nos ocupa, el riesgo que su muy precario estado constructivo motive su pérdida irreparable, nos lleva a denunciar que, si no se toman las medidas oportunas, el colapso de lo que aún queda erguido es inminente. El presente artículo pretende informar sobre su estado constructivo y patológico, como base sobre la que fundamentar una posible consolidación de los restos que asegure su pervivencia.

Sacramenia se localiza al norte de la provincia de Segovia $^{1}$. Las ruinas de la Ermita de San Miguel destacan en una ligera altiplanicie que sobresale de la paramera castellana (1). La complejidad arqueológica del enclave motivó que, en su estudio, fueran necesarias distintas disciplinas profesionales (2). Las primeras excavaciones encontraron, asociados a la Ermita, ciertos vestigios arqueológicos tallados en la roca caliza que da forma al cerro ${ }^{2}$. Se trata de diversos enterramientos pseudo-excavados en la roca sobre la que se asienta la iglesia (a su alrededor y en el ábside). Además, en el corte del cerro se aprecian unas covachas que podría tratarse, según especialistas, de un eremitorio alto-medieval. Tanto los enterramientos como las covachas no son objeto de este artículo. Sino, más bien, informar del estado constructivo-patológico de las ruinas, por más que los datos de estos estudios se tomen como referencia (3).

\section{DESCRIPCIÓN GENERAL DE LA ERMITA}

Es un edificio de pequeñas dimensiones (ver Figura 1), de una sola nave con ábside de sillería bien aparejada. Los muros de la nave son de fábrica de hormigón ciclópeo, formado por mampuestos, ripios y guijarros mezclados con mortero de cal y ejecutado con técnica de tapial con mechinales pasantes y encofrado a doble cara, formando un paramento tosco que, según algunos testigos aún presentes en sus muros, estuvo enfoscado y enlucido, al interior y exterior. Aún conserva, en algunas zonas del interior, restos policromados. La nave, según sus testigos y modelos análogos, tuvo techumbre de madera, hoy totalmente desaparecida, que se presentaba unida por su tramo recto presbiterial a un solo ábside semicircular y abovedado, en donde, por ser el centro litúrgico del edificio, se concentran los mayores esfuerzos constructivos, tanto en la fábrica, de cantería, como en la decoración iconográfica exterior e interior (mediante capiteles historiados y con motivos vegetales). Estos tienen refrendo en la portada de acceso meridional, también de sillería no concertada y bien aparejada, que destaca del plano del muro y señala, con rotundidad, el acceso lateral. Las irregularidades manifiestas del aula, desviada hacia el sureste con respecto al eje longitudinal del ábside, y de la portada, adosándose a su mampostería enfoscada, junto a detalles tales como el chapado de la sillería románica sobre los muros, en el lado sur del tramo recto de la cabecera, son argumentos que hacen pensar en un centro litúrgico anterior (4). Asimismo, la situación de la iglesia en lo alto de un cerro dominando la actual población de Sacramenia, junto a la gran planicie que se extiende al este de aquella, podría ser un antiguo núcleo habitado en continuidad a la iglesia ${ }^{3}$.

En las ruinas de la iglesia se distinguen tres espacios, manifestados al exterior por su volumetría (ver planimetría en Figura 2): 1, la nave de la iglesia, de disposición longitudinal y con acceso lateral al sur, de la que faltan sus cubiertas y su hastial occidental; 2, el tramo recto presbiterial, cubierto con bóveda de cañón que conecta la nave con el ábside y se remata superiormente por una arco triunfal que recibía el piñón de la cubierta; y 3, el ábside semicircular cubierto con una semicúpula (bóveda de toro).

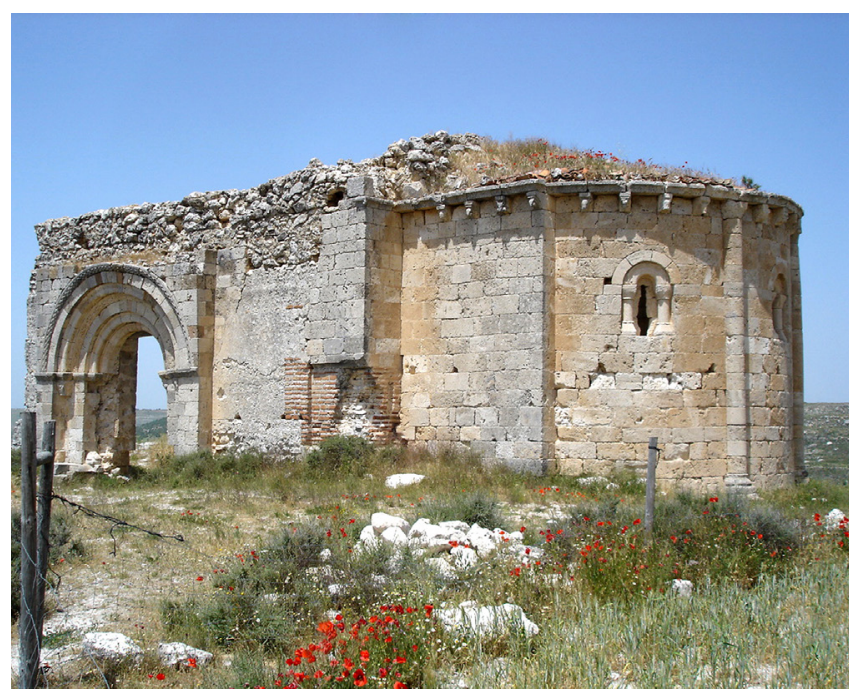

Figura 1. Estado actual de las ruinas de la Ermita desde su lateral sur-este (fotografía del autor).

\footnotetext{
El caserío de la Villa se asienta en el margen derecho de una paramera del río Sacramenia (afluente del Duratón, en la cuenca media del Duero), sobre un páramo calcáreo, a $830 \mathrm{~m}$ de altura, donde los ríos han abierto cauces amplios. La Ermita ocupa la posición noroeste, a 923 m de altura, que comparte, gracias a la sensible planitud del altozano, con el resto del cerro.

2 Según estas primeras excavaciones se ha descubierto un centro funerario de considerables dimensiones. En concreto en el lateral sur de la iglesia, así como en su interior, son visibles restos de enterramientos medievales antropomorfos pseudo-excavados en la roca. A esto se añade las numerosas covachas talladas en el corte sur y oeste de la escarpadura, e incluso avanzan por debajo de la Iglesia, y que pueden formar un eremitorio altomedieval de cierta complejidad, que aún queda por estudiar en profundidad (su protección es urgente, pues muy recientemente se ha producido la explanación alrededor de la iglesia, por delante de las cuevas, promovida por el Ayuntamiento de Sacramenia, con objeto de evitar el posible desprendimiento y caída sobre las casas del pueblo de grandes piedras procedentes de las embocaduras de las cuevas). Por otro lado, el conjunto de enterramientos y covachas ponen de manifiesto la existencia de un asentamiento de cierta complejidad que, según autores, podría extenderse por el resto de la superficie horizontal del cerro.

3 Esta idea toma fuerza por la necrópolis de tumbas antropomorfas excavada en la roca, algunas de las cuales están en el ábside, y refuerzan la hipótesis cronológica que sitúa la fundación del edificio en torno al s.X.
} 

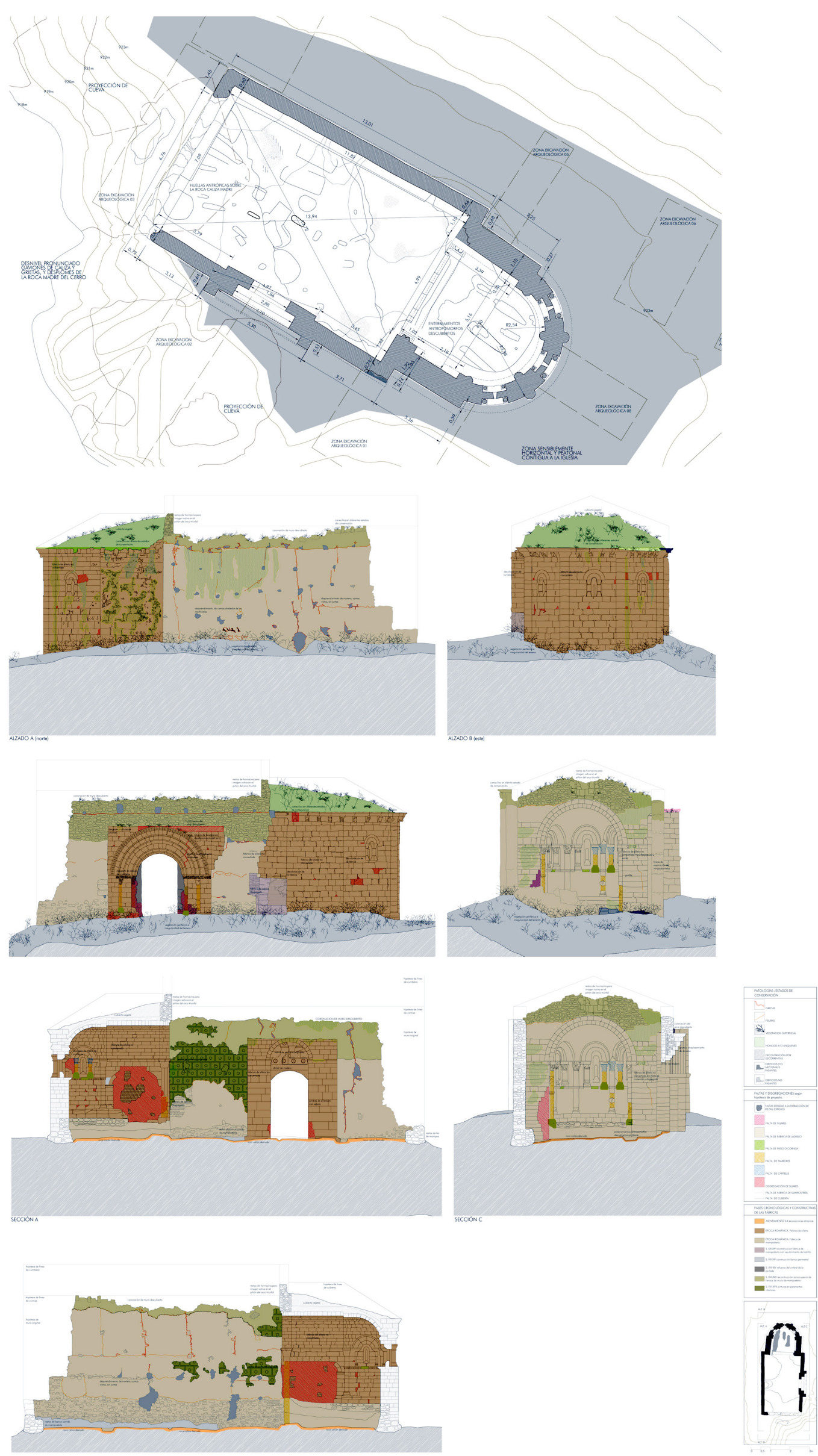

Figura 2. Estudio gráfico constructivo-patológico de la Ermita. Se recogen las patologías principales de su estado constructivo, que se reconocen según un examen visual. Planta de la ermita (arriba), alzados (centro) y secciones (abajo) (Dibujos del autor). 


\section{ESTUDIO CONSTRUCTIVO-PATOLÓGICO DE LOS RESTOS (5)}

La actual fábrica de San Miguel se ha venido fechando hacia mediados del XIII. Datación basada en las similitudes estilísticas y constructivo-estructurales con otras iglesias vecinas ${ }^{4}$. La presencia no obstante de los referidos restos antrópicos, dentro y fuera del edificio (hábitat rupestre y enterramientos antropomorfos), nos informa de que el lugar ya vendría siendo ocupado por un asentamiento humano al menos desde el siglo X, más en concreto, a partir del año 940 .

Atendiendo a los elementos constructivos que quedan actualmente en pie, como se ha expuesto anteriormente, y a las cuatro fases constructivas referidas, se desarrolla el siguiente estudio (la descripción de las siguientes unidades constructivas se corresponde con el levantamiento gráfico recogido en la Figura 2 (6).

\subsection{Nave de la iglesia, niveles basamentales (7)}

Se aprecia una estructura perimetral a toda la base del muro $\mathrm{N}$ y a la mitad del muro $\mathrm{O}$ de la iglesia de factura muy basta, caótica, realizada a base mampuesto, ripio y otros restos constructivos. Sólo en la pared O ofrece cierta uniformidad, con una fábrica más regular construida con sillarejos de caliza y toba distribuidos en dos hiladas. Se trata de un banco corrido adosado a la pared mediante un mortero potente y muy compacto, de tonalidad amarillenta y fabricado a base de arena, pellas de cal, clastos de caliza y fragmentos de teja curva. La presencia de este mortero, con las huellas o negativos de los mampuestos que en su día trabó, en otros puntos de la iglesia -a ambos lados del arco triunfal y en un tramo del muro S- permite asegurar que dicho banco se prolongaba por la mayor parte del perímetro interno de la nave. En la esquina SE, además, se mantienen restos de la capa de revestimiento de cal que en origen cubría y uniformiza toda la estructura, prolongándose también por las paredes del templo.

La cimentación es de profundidad muy escasa, pues apoya casi directamente sobre la roca caliza del cerro a través de cimientos de escasa elevación y sección. Combinan mampuesto muy irregular, ripio y restos constructivos, cohesionados con argamasa de caliza y barro. El grosor de la cimentación y su fábrica se aprecia en todo el interior de la nave, ya que, tras el estudio, ha quedado al descubierto. Se encuentra mal rejuntada, con las juntas lavadas, erosionada, con numerosos mampuestos descalzados y sin cohesión con la fábrica superior. Algunas zonas se aprecian rejuntadas con restos de ladrillo y cemento fruto de sus distintas fases constructivas (8). $\mathrm{Al}$ exterior, la cimentación de la nave queda cubierta por distintas capas de tierra y derrumbes que se han acumulado en su discurrir por el tiempo.

Se han documentado distintos pavimentos, de mortero de cal, en sucesivas capas, sobre cama de arena de nivelación. El grosor de estos varía en función de las necesidades del terreno para conseguir una superficie uniforme con el fin de asentar el pavimento de cal señalado.
A occidente se denotan los restos de la cimentación del hastial que configuraba la portada, imafronte, a los pies de la iglesia. Los restos se aprecian a distinta cota en todo su trazado, y van disminuyendo progresivamente de $\mathrm{N}(120 \mathrm{~cm}$.) a S $(20 \mathrm{~cm}$.).

La documentación del suelo está completamente alterada en toda la mitad $\mathrm{N}$ de la nave a causa de un amplio y profundo corte de planta irregular que se ha documentado desde las cotas más superficiales hasta la base rocosa. Corresponde a un hoyo de saqueo, practicado, a buen seguro, a mediados del siglo pasado para robar material constructivo procedente del derrumbe de la iglesia. Así lo certifican varios vecinos de la localidad, según el estudio referido.

Los pavimentos documentados de cal sellaban numerosas y variadas fosas talladas en la superficie rocosa. Algunas de éstas forman parte del proceso constructivo del templo pero otras son anteriores a su edificación y pertenecen tanto a contextos funerarios como a domésticos. La dificultad en cuanto a su interpretación funcional y/o cronológica radica en que no se cuenta con una secuencia gradual de los restos sino que se trata de una estratigrafía horizontal en roca. El conjunto de hoyos, rebajes, fosas y otras subestructuras rupestres que se pueden asociar al proceso constructivo del templo románico es numeroso (ver Figura 2). En general se trata de espacios de almacenamiento de alimentos, tipo silo, de testimonios de fases constructivas, o de fosas funerarias. En relación a las fosas funerarias, de los 6 ejemplares documentados, todas ellas se localizan el tercio occidental de la nave, inmediatamente al $\mathrm{O}$ de una grieta natural profunda y muy remarcada que atraviesa en diagonal este sector. Están orientadas en dirección $\mathrm{O} / \mathrm{E}$, con ligeras desviaciones en dirección $\mathrm{SO} / \mathrm{NE}$.

\subsection{Muros de la nave, fábricas de encofrado de la fase románica (siglo XIII) (9)}

En el lienzo meridional, el septentrional y el occidental se levantan paramentos realizados mediante la superposición de tongadas de mortero y cantos recogidos mediante encofrado a dos caras. Marcando estas hiladas hallamos una serie de agujeros, mechinales, empleados para montar los encofrados durante la construcción, que presentan normalmente en su interior una pieza cerámica de forma semicircular que permitía la extracción de la pieza lignaria una vez fraguado el mortero (10). Estos probablemente se rellenaban una vez finalizada la obra. Hoy, la gran mayoría de ellos se aprecian vacíos.

Se ha establecido la contemporaneidad del lienzo septentrional con el ábside debido a que el paramento de sillería se imbrica con los encofrados. La presencia de sillares de esta primera fase, de toba con un módulo de $28 \mathrm{~cm}$, perfectamente alineados, insertos en el encofrado al oeste de la portada, indicarían como mínimo la contemporaneidad de las dos fábricas.

Es necesario señalar que en el lienzo norte se han distinguido dos unidades superpuestas en el encofrado que se han considerado de este mismo momento constructivo (11). Esta diferenciación se ha realizado debido a una mayor presencia de mortero en las tongadas superiores respecto de las inferiores. Sin embargo, la coincidencia entre los orificios de tongadas,

\footnotetext{
${ }^{4}$ La ermita sigue los designios formales de la «línea del Duero», siendo ejemplos próximos a ella la iglesia de San Esteban de Osma (Roa) o la iglesia de San Vicente Mártir de Pospozuelo, más cercana incluso a su estado ruinoso.
} 
así como su imbricación con la fábrica de sillería, muestran que fueron realizadas en la misma fase ${ }^{5}$.

\subsection{Partes reconstruidas de la nave (siglos XVI-XVII)}

En un momento indeterminado, tras la segunda fase constructiva, se produce la destrucción de la parte superior de los lienzos de la nave, tras la cual se acomete su reconstrucción. Sin embargo, en esta ocasión las nuevas fábricas no se erigen mediante sillares o tongadas de encofrado, sino que se emplea una mampostería de escasa calidad técnica. De hecho, son mampuestos de enorme heterogeneidad en su forma y tamaño unidos con gran cantidad de argamasa, entre los que se insertan sillares reutilizados de la primera iglesia.

Un ejemplo paradigmático de la escasa voluntad estética de los promotores de esta reconstrucción lo representa el vano abierto sobre el arco triunfal, entre el ábside y la nave. Apreciamos que los sillares utilizados para su construcción son en realidad elementos reutilizados, como fragmentos de fustes e impostas, colocados con bastante tosquedad. Asimismo, los tres únicos canes visibles en la nave, situados en el extremo occidental del muro norte, son en realidad reutilizaciones de elementos originales de la primera iglesia ${ }^{6}$.

Se desconoce si esta destrucción de los lienzos de la nave se produjo debido a un abandono de la iglesia o a causas violentas coyunturales, como un incendio. Del mismo modo, y asumiendo la segunda hipótesis, tampoco se puede determinar si tras la ruina se procedió a la reconstrucción inmediata del templo o si, por el contrario, pasaron varias décadas durante las cuales el lugar estuvo abandonado? ${ }^{7}$.

En general las fábricas de los muros de la nave, tanto de esta fase constructiva como de la anterior, han perdido casi por completo todos los recubrimientos que en su día la protegían y aparecen descarnadas. Se aprecian con escasa cohesión, disgregadas, faltas de rejuntado, y expuestas al azote del agua y viento, con numerosas fisuras, grietas y orificios. Sin embargo, no presenta humedades de importancia (por su permanente ventilación), y su aspecto general es vertical y bien aplomado.

Ambas fases constructivas murarias presentan fisuras y grietas que corren en la dirección longitudinal y transversal a los mechinales. Son fisuras de contracción y dilatación de la fábrica, que se ven ayudadas por la acción del agua, filtrada desde la coronación, que corre por el alma del muro hasta su evacuación por ambas caras. Por ello son más acusadas las verticales que las horizontales (agua por gravedad).

Los muros conservan un testigo de su altura a través de 3 canecillos en su extremo más occidental. En el resto ha desaparecido su coronación y remates de cornisa, entre 40 y $90 \mathrm{~cm}$ (con la configuración completa de apoyo y durmiente, que podría tener, para dar asiento a los pares/cerchas de la cubierta leñosa), dejando la fábrica expuesta. La acción del agua ha facilitado el crecimiento de vegetación, bien asentada, que hunde raíces en el interior del muro. También se aprecian hongos y líquenes en toda la superficie, con distribución irregular.

\subsection{Hastial occidental (colapsado)}

Como se ha comentado, los restos del hastial occidental se aprecian a distinta cota en todo su trazado, y van disminuyendo progresivamente de $\mathrm{N}\left(120 \mathrm{~cm}\right.$.) a $\mathrm{S}(20 \mathrm{~cm} \text {. })^{8}$. Tienen $60 \mathrm{~cm}$. de anchura y su sistema constructivo es igual al del resto de la nave -encofrados de mampuesto y ripio mezclado con barro y algo de cal-. En el tramo central del muro hay dos cortes correspondientes al vano de una puerta cuya estructura se documenta con mayor precisión en el alzado del paramento exterior. Se trata de una jamba de ladrillos macizos adosada a sendos cortes; la del lado N es una simple hilada de losetas colocadas de canto, mientras que en la opuesta las losetas se disponen en horizontal alternando con capas de mortero del mismo grosor. Con posterioridad se adosa una jamba de piedra a cada una de estas paredes (un sillar vertical de caliza). La última actuación efectuada en este punto es el cegamiento del hueco con escombro ${ }^{9}$.

En el estudio constructivo del basamento se ha detectado, además de excavaciones antrópicas provenientes de los asentamientos del s.X. y del umbral del hueco de acceso referido, un interesante espacio asociado al templo en el extremo $\mathrm{N}$ del hastial. Ello ha sido posible gracias al descubrimiento de un muro perpendicular cuya factura y posición estratigráfica denotan que es diferente y posterior a la fábrica del templo ${ }^{10}$.

El desplome del hastial se produjo en Época Contemporánea, según los estudio realizados, casi con toda seguridad durante el transcurso de la Guerra de la Independencia.

\footnotetext{
5 Atendiendo a los caracteres formales descritos para esta primera iglesia es evidente la voluntad de los constructores de resaltar principalmente la mitad meridional del templo, quizá porque lindaba con un espacio central de la vida aldeana de Sacramenia. De hecho, mientras que todo el muro septentrional de la nave está realizado con técnicas de encofrado, el lienzo sur dispone de una portada monumental, así como paramentos en sillería. Por otro lado, el vano oriental y el situado en la mitad meridional del ábside disponen de capiteles decorados, cuando los del ventanal norte son lisos. Finalmente en la mitad sur del ábside hallamos hasta cinco grabados cruciformes que desaparecen en la fábrica septentrional.

${ }^{6}$ De hecho, dos de estos canes disponen de la referida decoración vegetal a base de tallos con frutos redondeados que encontramos en numerosos elementos de la fase románica.

7 El emplazamiento cronológico de este periodo supone también un problema, ya que no se cuenta con ningún indicador en el que apoyarse. Únicamente se podría considerar la cuarta fase, que engloba diversas pinturas realizadas en el ábside y la nave, como contemporánea y extrapolar, de ahí, su cronología de época moderna (a pesar de no contar con ninguna evidencia que nos asegure la contemporaneidad de estas dos fases).

${ }^{8}$ El elemento más sobresaliente del hastial colapsado consistía en un fragmento localizado a los pies cuyo sistema constructivo era el mismo al de los muros existentes. Este paramento se desmoronó muy recientemente, durante su estudio. La fábrica era de mampuesto y ripio de piedra caliza trabado con argamasa de arena, cal y canto. El porcentaje de arena era bastante elevado lo que provocaba que tuviera poca consistencia y finalmente se desmoronara.

9 Se desconoce la fecha de este cegamiento, pero probablemente próximo a la última reforma.

${ }^{10} \mathrm{Su}$ zanja de cimentación, que corta al nivel del escombro anterior, indica que puede tratarse de un zócalo sobre el que asienta un pórtico (ver nota siguiente).
} 


\subsection{Portada meridional}

Se repasan las dos fases constructivas reconocidas ${ }^{11}$ :

- Fase románica (siglo XIII): Su mitad exterior está compuesta por un arco de medio punto realizado con siete arquivol$\operatorname{tas}^{12}$. Este arco descansa sobre dos sillares verticales que disponen en su parte superior de impostas (ornamentación vegetal), así como sendas columnas (sólo sobreviven dos capiteles desfigurados $)^{13}$. El interior de la portada tiene dos grandes jambas con sendas impostas de sección cóncava, y extremo saliente vertical en su parte superior, sobre las que se apoya un pequeño arco semicircular, realizado con una única hilada de dovelas (sin ornamentación). Como este arco se encuentra a mayor altura respecto al exterior, se incorpora, en el hueco entre ambos, un paramento de sillares apoyado precariamente sobre un dintel de madera ${ }^{14}$.

- Reforma (siglos XIII-XIV): En la segunda fase constructiva se reconstruyó el tramo entre la portada meridional y el ábside. Estratigráficamente una reforma está marcada en el muro por un corte que destruye parte de los elementos anteriores, y las nuevas unidades que lo rellenan. Entre éstas últimas podemos diferenciar dos tipos de fábricas: por un lado, el encofrado de mortero y canto con un recubrimiento de ladrillos o de sillares según hallamos en el esquinal que muestra el final de la nave y el principio del ábside, justo bajo el paramento de sillares. Cabe señalar que la transición entre la sillería de la primera fase y la reforma está marcada en este esquinal por una hilada de sillares con la mitad inferior de su cara vista cóncava. Por otro lado, los encofrados de las fábricas de recubrimiento que se emplean aquí evidencian las tongadas del encofrado con diversos agujeros alineados. Toda esta reforma se apoya sobre un paramento de mampostería que sólo es visible desde el interior. Se compone de bloques calizos en los que al menos sus dos caras mayores han sido regularizadas, unidas con argamasa y dispuestas en diagonal respetando una hilada horizontal. Es necesario señalar que los ladrillos empleados en toda esta fase, tanto en las fábricas de recubrimiento mencionadas como en los cimientos, disponen de la misma heterogeneidad formal que los de la primera iglesia, por lo que resulta factible que fueran reutilizados de la misma estructura que éstos ${ }^{15}$.
Respecto a las causas que pudieron motivar esta reconstrucción parcial se pueden aducir graves problemas estructurales que afectaron a los sillares situados entre el ábside y la portada. De hecho, las fábricas de sillería que originalmente debieron estar unidas fueron cortadas, quizá por un derrumbe que acabaría impulsando la reforma (12). En cualquier caso, el hecho de que esta zona se reformara a base de encofrados mostraría sustancialmente la voluntad de los promotores de aprovecharse de la solidez estructural de esta técnica constructiva, más que una limitada capacidad de recursos. En esta reforma, por tanto, habrían primado motivaciones de carácter práctico por encima de estéticos ${ }^{16}$.

\subsection{Cabecera, lectura exterior, niveles basamentales}

Se ha detectado una potente cimentación del ábside románico. Se trata de una estructura construida con bloques de caliza de mediano y gran tamaño sin desbastar, trabados con una potente capa de mortero de cal y canto. Tiene una altura total de $75 \mathrm{~cm}$ (según el estudio in situ) distribuida en tres hiladas irregulares aunque bien diferenciadas. Apoya directamente sobre el substrato geológico en el que se ha practicado un suave repicado para dejarlo enrasado y nivelado. Esta estructura sobresale entre 28 y $42 \mathrm{~cm}$ de la línea de fachada -pared E del ábside construida con sillares-. A mediados del siglo XIII se construyó el ábside románico y para su cimentación se abrió una fosa que corta al depósito sedimentario que cubría las tumbas rupestres.

\subsection{Tramo recto presbiterial y ábside, lectura interior, niveles basamentales}

Todo el espacio interior del ábside se encuentra al ras de la superficie rocosa, limpio por completo de cualquier tipo de depósito sedimentario de carácter antrópico. De esta manera queda al aire la cimentación del ábside románico y las distintas subestructuras talladas en la superficie rocosa. El único sedimento que cubre este ámbito y rellena las fosas rupestres es natural, de carácter post-deposicional, procedente del arrastre del viento ${ }^{17}$.

Entre estas subestructuras se pueden diferenciar perfectamente las que corresponden al proceso constructivo y al momento de uso de la iglesia románica, de las que ya existían con anterioridad a la construcción del templo. Se han distinguido sepulturas prerrománicas en fosas excavadas en la roca. Es-

\footnotetext{
${ }^{11}$ Fruto del estudio arqueológico se ha documentado la localización de un zócalo que cerraba el flanco oriental de un pórtico que protegía la fachada sur. A decir por su ubicación respecto a la planta general del templo, y por su posición estratigráfica, es posterior a la construcción románica, pudiéndose fechar en la Baja Edad Media o Época Moderna. Este zócalo no asienta sobre la roca caliza sino que lo hace directamente sobre las cubiertas de varias tumbas rupestres subyacentes.

${ }^{12}$ De las cuales cinco presentan decoración: la primera, desde el exterior, un ajedrezado de tres hiladas, la tercera y la quinta simples acanaladuras rectangulares, y la cuarta y la séptima motivos vegetales.

${ }^{13}$ Decorados con motivos animales y uno con la recurrida decoración a base de elementos vegetales.

${ }^{14}$ Este elemento lignario ha sido adscrito a esta primera iglesia debido a la imposibilidad de determinar, sin los pertinentes análisis radiocarbónicos o dendrocronológicos, si es el original de la primera iglesia o fue añadido en una reconstrucción posterior.

15 En uno de los sondeos realizados en el exterior de la iglesia se han sacado a la luz los cimientos de esta reforma, siendo de mayor profundidad que los identificados en la zona absidal, aunque también de mampostería y con hiladas de ladrillos a modo de zapata de cimentación.

${ }^{16}$ No se cuenta con indicadores temporales que permitan establecer una cronología absoluta fiable para esta segunda fase constructiva. Con todo ello, y a partir de ciertos indicios, se puede indicar que la reforma no se realizó en un momento muy posterior a la construcción de la primera iglesia, quizá en el propio siglo XIII. De hecho, el empleo de idénticas técnicas de encofrado, así como la reutilización de los mismos ladrillos identificados en la primera iglesia evidenciarían el breve lapso de tiempo que separa ambos momentos constructivos. Al respecto, se asume que no son indicios excesivamente sólidos, pero es todo lo que se puede establecer a partir de la información obtenida con la lectura estratigráfica de los alzados.

${ }^{17}$ No se tiene constancia cierta de quién o cómo se efectuó la «excavación» o vaciado del interior del ábside pero la tradición oral de la localidad señala a Teodoro Santos, «maestro» de Sacramenia, a mediados del siglo pasado, como artífice de esta actuación dentro de la llamada «operación rescate». La profesora M. ${ }^{a}$ Golvano Herrero ya lo conoce en tal estado en el año 1973, cuando efectuó la intervención arqueológica en la cercana necrópolis rupestre de Fuentidueña.
} 
tas se distribuyen aleatoriamente por el espacio semicircular del ábside sin apenas interferir en el tramo presbiterial. Están orientadas en dirección $\mathrm{O} / \mathrm{E}$ (cabecera/pies) siguiendo con bastante exactitud el eje longitudinal del templo. Ninguna de ellas conserva el más mínimo resto de cubierta y, fruto del expolio, tampoco contienen restos humanos (13). Desde el punto de vista formal todas presentan planta antropomorfa bastante simétrica, con hombros perfectamente definidos, si bien cada una tiene sus detalles constructivos específicos. Además, se observa en el extremo del eje absidial un hoyo rupestre de planta cuadrada (14 $\mathrm{cm}$ de lado), posiblemente destinado a encajar la base del tenante de altar. Las fosas funerarias que reciben directamente la cimentación del ábside están provocando un ligero descalce de la fábrica, en la que se aprecia, en su base, el descenso de algunos sillares.

A la altura del arco triunfal el mortero presenta un corte o cajeado destinado a asentar el escalón que conecta el ábside con la nave. Tiene $22 \mathrm{~cm}$ de altura y la misma longitud que el vano del arco. En su extremo $\mathrm{S}$ se mantienen las tres únicas piedras alineadas que se conservan del peldaño original. Se trata de bloques rectangulares, bien regularizados en sus dos planos visibles -superficie y cara frontal- y trabados con mortero de cal y canto. Dicho mortero sí se conserva en el resto del trazado, de hecho están perfectamente marcadas las huellas o negativos de las piedras que faltan, un total de 5 , que completarían todo el escalón. Se denota también un estrecho hueco que queda entre las piedras originales del peldaño y el corte efectuado para asentarlas.

Inmediatamente al E y paralela al peldaño se extiende una banda de mortero de cal y canto, uniforme y nivelada, de $32 \mathrm{~cm}$. de anchura. Es una superficie regularizada, posible base para fijar un pavimento de losas o baldosas, aunque la explicación más convincente es considerar que sirvió para sentar un segundo escalón, necesario para igualar con el nivel de suelo cuya cota está perfectamente señalada en la base de las paredes del ábside.

\section{8. Ábside, fase románica (siglo XIII)}

Se puede establecer la vinculación entre portada y ábside en el mismo periodo románico, al compartir ambas la misma técnica constructiva e idénticas formas decorativas. Ciertamente se utiliza en ambas el mismo tipo de paramento de sillares, compuesto por bloques calizos, algunos de ellos de toba, de coloración diversa, dispuestos a soga en hiladas horizontales de módulo homogéneo (28-32 cm la mayoría, pudiendo ser algunos de menor tamaño, de 20-25 cm), longitud diversa (máximo $64 \mathrm{~cm}$; mínimo $14 \mathrm{~cm}$., aunque la mayoría oscilan entre los 45-55 cm) y juntas estrechas de 1-3 $\mathrm{cm}$ de espesor. Estos sillares recibieron además una talla final con tallante a $45^{\circ}$, tal y como puede evidenciarse por las finas líneas en diagonal de su cara vista ${ }^{18}$.

El paramento exterior del ábside dispone de dos tramos rectos paralelos (tramo recto presbiterial) unidos por uno semicircular (ábside propiamente dicho). Este último cuerpo absidial se denota dividido, al exterior, en tres paños, cada uno con un vano en su punto medio, enmarcado por dos semi-columnas no decoradas. En su cornisa, encontramos una hilada de canecillos con decoración variada. Es destacable que si bien en las naves sólo permanecen 3 canecillos del muro norte ${ }^{19}$, en el ábside los canecillos se reconocen bien, por más que muchos presenten mutilaciones y faltas en su decoración. La mejor calidad constructiva ha favorecido su conservación. La decoración de los canecillos aún reconocibles repite una talla entre lo geométrico vegetal y lo animalesco. Su descripción y estado actual se corresponde con:

Lateral norte del ábside: $1^{\mathrm{o}}$, liso; $2^{\mathrm{O}}$ y $3^{\mathrm{o}}$, escalonados invertidos con bola y dardo; $4^{\circ}$. Liso; $5^{\circ}$. Escalonados invertidos con modillón de dos molduras; $6^{\circ}$. Igual al $2^{\mathrm{O}}-3^{\mathrm{o}} ; 7^{\mathrm{o}}$. Igual al $5^{\mathrm{o}} ; 8^{\mathrm{o}}$. Igual a $2^{\mathrm{O}}-3^{\mathrm{O}} ; 9^{\mathrm{O}}$. Igual al $2^{\mathrm{O}}-3^{\mathrm{O}} ; 10^{\mathrm{o}}$. Escalonado invertido roto; $11^{\mathrm{o}}$. Igual a $10^{\mathrm{O}} ; 12^{\mathrm{O}}$. Igual a $2^{\mathrm{O}}-3^{\mathrm{O}} ; 13^{\mathrm{O}}$. Cara de felino; $14^{\circ}$. Roto; $15^{\circ}$. Igual a $2^{\mathrm{O}}-3^{\mathrm{o}} ; 16^{\mathrm{o}}$. Roto.

Lateral sur del ábside: $17^{\circ}$. Cabeza de felino, $18^{\circ}$. Cabeza humana con bucles, desfigurada; $19^{\circ}$. Cabeza de buey; $20^{\circ}$. Cabeza de jabalí, desfigurada; $2^{\circ}$. Escalonado invertido; $22^{\circ}$. Cabeza de buey; $23^{\circ}$. Igual a $2^{\mathrm{O}}-3^{\mathrm{O}} ; 24^{\mathrm{O}}$. Cabeza de jabalí; $25^{\mathrm{O}}$. Igual a $2^{0}-3^{0} ; 26^{0}$. Cabeza de buey, roto y muy desfigurada; $27^{\circ}$. Roto.

Sobre los canes se sitúa un alero de morfología cóncava en el que se apoyaría el tejado, hoy desaparecido ${ }^{20}$. El trasdós de la bóveda está cubierto de escombro y tierra, proveniente a buen seguro del mismo colapso del tejado. La vegetación ha hundido allí sus raíces. No obstante, no presenta filtraciones importantes por dentro, pues la tierra, ya compactada, ejerce cierta función hidrófuga.

En el interior del presbiterio se mantiene la misma disposición mencionada al exterior. Sus tramos rectos están cubiertos por dos dobles arcadas ciegas, de las que únicamente se conserva los arranques del arco más oriental, al haber sido saqueadas. Sobre estos arcos hay un estrecho paramento de sillería en el que se apoya una imposta de sección cóncava y extremo saliente vertical que actúa de división entre los muros y la cubierta de bóveda de medio cañón ${ }^{21}$.

\footnotetext{
${ }^{18}$ Asimismo, los diversos motivos ornamentales mencionados para la portada se hallan en el ábside: ajedrezado, imposta de sección cóncava y extremo saliente vertical o motivos vegetales.

${ }^{19}$ Lo cual es un importante dato pues informa de la altura de la cornisa de la nave. El resto de canes desaparecieron junto con la coronación de estos muros y su cornisa.

${ }^{20}$ La decoración vegetal se realiza mediante un tallo del que pende un fruto redondeado y que hallamos en otros elementos del ábside. Cabe señalar que en la mitad meridional del ábside se han identificado, realizados sobre los sillares más próximos a la cornisa, cinco grabados cruciformes de cronología indeterminada.

${ }^{21}$ Su tramo semicircular está también dividido en tres espacios marcados por los tres vanos flanqueados por cuatro semi-columnas adosadas. Cada uno de estos vanos estaba originalmente compuesto en su interior por dos columnas con decoración vegetal en sus capiteles aunque únicamente se conservan las dos del vano septentrional. Esta decoración vegetal se repite en las caras exteriores de los ventanales, siendo los capiteles del vano restante lisos. Por lo que a las semi-columnas interiores se refiere, las dos situadas en los extremos del tramo semicircular del ábside presentaban una decoración a base de motivos animales, mientras que las otras dos dispusieron de ornamentación vegetal, habiéndose conservado sólo el capitel de la mitad septentrional. Estas semi-columnas disponen en la parte superior de sus capiteles, asimismo, de decoración a base de tallos con frutos redondeados, idéntica a la documentada en algunos de los canecillos del ábside y que hallamos también en los capiteles del arco triunfal, y en la imposta que recorre el muro dirección N-S que une el ábside con la nave.
} 
La morfología semicircular de este extremo del ábside obliga a cambiar el tipo de cubierta que se había utilizado en el tramo recto, realizándose una bóveda de horno que descansa en las cuatro semi-columnas referidas.

La cimentación de la zona absidal, sobre la que se apoya el muro de sillería, está realizada con mampuestos desbastados de morfología cuadrangular y tamaño bastante homogéneo dispuestos en hiladas horizontales. Es visible en el interior del ábside, al haberse excavado previamente, y en los dos sondeos realizados al exterior.

$\mathrm{Al}$ oeste de las dobles arcadas ciegas, marcando la entrada al ábside desde la nave, se sitúa el arco triunfal de medio punto que se apoya en dos columnas de las que sólo se conservan, de la septentrional, el capitel, y de la meridional, el capitel, parte del fuste y la basa ${ }^{22}$. Debido a la diferencia de anchura entre el ábside y la nave, la unión entre ambas fábricas se realiza con sendos paramentos en sillería que parten del arco triunfal hacia el extremo oriental de los lienzos norte y sur ${ }^{23}$.

La sillería de estas dos fábricas de la primera fase destaca por su gran homogeneidad. Ciertamente, estos paramentos se realizan con bloques calizos paralelepípedos dispuestos fundamentalmente a soga en hiladas horizontales de módulo regular, siendo la gran mayoría de $28-32 \mathrm{~cm}$. La longitud de los bloques es diversa, oscilando entre los 14 y los $64 \mathrm{~cm}$, mientras que, debido a su regularidad, sus juntas son estrechas (1-3 cm). Los bloques combinan la caliza, más compacta y pesada, con la toba ${ }^{24}$. También reflejan, a través de las finas líneas diagonales y paralelas que hallamos en su cara vista, el empleo del trinchante a $45^{\circ}$ para la realización de la talla final.

Se ha de añadir, asimismo, que, a modo de ripios, zapatas de cimentación o simplemente insertos entre las tongadas de encofrado, y contemporáneos a la realización de esta primera iglesia, se hallan numerosos ladrillos realizados mediante cocción oxidante, con gruesos y diversos desgrasantes. La diversidad en sus dimensiones hace pensar que se trate de elementos constructivos reutilizados de algún edificio anterior a lo largo de esta primera fase o de la segunda.

\subsection{Entorno próximo}

En el flanco oriental del cerro, muy próximo al extremo N, se ha documentado un alineamiento de piedras trabadas con mortero $^{25}$. Se localiza en el mismo borde de la plataforma, a la altura de la primera estaca de madera que marca el inicio del vallado en dirección $\mathrm{S}$. A simple vista se trata de tres bloques de caliza de mediano tamaño, muy irregulares y voluminosos, alineados en dirección N/S. El mortero empleado es una mezcla de arena, cal y canto. No se puede establecer más precisiones al respecto, pues sería necesaria una intervención de mayor envergadura para poder determinar el alcance real de estos restos tan exiguos que suponemos son los que se atribuyen a un bastión arruinado. Este elemento, por sí mismo y con una documentación tan precaria, resulta insuficiente para establecer una tipología concreta, pero teniendo en cuenta el muro de gran envergadura documentado en el extremo opuesto del cerro - NO- y al que se ha atribuido un marcado carácter defensivo, sin que por el momento se pueda establecer una conexión directa entre ambos elementos.

Por último no debe pasarse por alto la existencia, en la mitad oriental de la parcela, de fragmentos de cerámica elaborada a mano (14). Aparecen de forma muy dispersa y mezclados con los restos constructivos. Son fragmentos pequeños, con las superficies muy rodadas. Esta producción manufacturada podría estar asociada a la ocupación medieval del cerro pero, teniendo en cuenta el elevado potencial de este enclave y las condiciones favorables que ofrece como emplazamiento destacado desde el que se ejerce un amplio dominio visual del valle, en absoluto se puede descartar la existencia de un asentamiento prehistórico previo y arrasado por la repoblación medieval ${ }^{26}$.

\section{CONCLUSIONES:}

\subsection{Evolución cronológico-arquitectónica de la Ermita}

A partir de los estudios realizados, y de la secuencia estratigráfica descubierta, se pueden establecer cuatro fases constructivas:

La primera es una construcción del s.X, adaptada a los restos de una construcción previa de la que no se guardan prácticamente datos sobre las fábricas existentes.

La segunda es su fase románica del s.XIII, que levantó el templo sobre la construcción anterior.

Y la tercera y cuarta son reformas tardías, de las que hay referencias se produjeron entre los siglos XVI, XVII y XVIII cuando se realizaron distintas obras de mejora en las iglesias de Sacramenia, entre ellas en la de San Miguel.

\subsection{Proceso constructivo}

$1^{\mathrm{a}}$ : El cuerpo constructivo principal románico, que actualmente puede contemplarse $\left(1^{\text {a }} 1 / 2\right.$ siglo XIII), se construye amortizando un espacio cementerial anterior ${ }^{27}$.

$2^{\mathrm{a}}$ : Se evidencia una dualidad constructiva de esta primera iglesia románica, ya que se construyen con sillería las zonas

\footnotetext{
${ }^{22}$ La decoración se limita exclusivamente a los capiteles: una figura humana montada en un animal mitológico y lo que parece un bóvido. Al igual, que las semi-columnas del tramo semicircular del ábside, ambas tienen en su parte superior de sus capiteles una franja decorada con tallos de los que penden frutos redondeados.

${ }^{23}$ A la altura de los capiteles de este arco se dispone una imposta decorada con los mismos motivos vegetales mencionados más arriba, a base de tallos con frutos redondeados, que actúa de separación entre los dos paramentos de sillares diferenciados. Cabe mencionar que los paramentos superiores fueron en origen la misma fábrica hasta que les afectó el corte posterior.

${ }^{24}$ Estos se caracterizan por su porosidad y ligereza que la hace perfecta para cubiertas abovedadas, como podemos evidenciar de su abundante presencia en la bóveda del ábside.

${ }_{25}$ Podría ser el origen del topónimo «sacramenia»: del latín, sacra moenia, ruinas sagradas.

${ }^{26}$ Los restos no presentan rasgos específicos que ayuden a centrar la ocupación en un momento concreto de la prehistoria.

${ }^{27}$ La presencia de necrópolis exentas no es algo excepcional, habiéndose identificado en numerosas aldeas de cronología altomedieval en ese ámbito territorial.
} 
más monumentales, mientras que el resto se levanta con sencillos encofrados de mortero y canto ${ }^{28}$.

$3^{\mathrm{a}}$. Esta primera iglesia tuvo problemas estructurales en el muro sur solucionados, no mucho tiempo después, con una reforma en la que primaron valores prácticos sobre estéticos, al llevarse a cabo esencialmente con encofrados en una zona donde primaba la fábrica de sillería.

$4^{\mathrm{a}}$. Se ha documentado una destrucción parcial del templo, durante la Guerra de la Independencia, seguida de una reconstrucción de escasa calidad técnica (última fase constructiva identificada, pues no se conocen actuaciones sobre la ermita posteriores).

\subsection{Consolidación}

Muchos son, como se ha repasado en las anteriores líneas, los motivos de preocupación sobre el estado constructivo de la Ermita de San Miguel de Sacramenia. Lo deseable, para evitar el seguro colapso al que se puede ver abocada, sería consolidar lo que aún permanece en pie y los interesantes vestigios del interior del templo y periferia más cercana. Esta consolidación debería llevarse a cabo bajo criterios modernos, para no alterar su lectura (15). De este modo no se perdería este ejemplo de arquitectura y, lo que se antoja más valioso, su comprensión como documento histórico, sujeto, en el futuro, a nuevos estudios y conclusiones.

\section{REFERENCIAS}

(1) Tejero, J. M. (dir.). (1988). Análisis del Medio Físico de Segovia. Delimitación de Unidades y estructura territorial. Valladolid: Junta de Castilla y León. Consejería de Fomento.

(2) Palomino, A. L., Negredo, M. J. (2008). Iglesia de San Miguel en Sacramenia (Segovia): excavación arqueológica y prospección intensiva del entorno. Informe técnico inédito. Valladolid: Dirección General de Patrimonio y Bienes Culturales, Consejería de Cultura, Junta de Castilla y León.

(3) Aratikos Arqueólogos SL. (2003). Trabajos de excavación arqueológica de urgencia en el cementerio Altomedieval de San Martín, Fuentidueña (Segovia). Informe técnico inédito. Segovia: Servicio Territorial de Cultura de Segovia, Junta de Castilla y León.

(4) Ruiz, I. (1998). El Románico de Villas y Tierras de Segovia. Valladolid: Encuentro Ediciones.

(5) Latorre-González, P., Caballero, L. (1995). La importancia del análisis estratigráfico de las construcciones históricas en el debate sobre la restauración monumental. Informes de la Construcción, 46(435): 5-18, doi: http://dx.doi.org/10.3989/ ic.1995.v46.i435.1093.

(6) Represa, I. (1998). El diagnóstico en la restauración arquitectónica. Restauración arquitectónica, 1(2): $177-184$.

(7) Quirós, J. A. (2002). Arqueología de la arquitectura en España. Arqueología de la Arquitectura, 1(1): 27-38.

(8) Caballero, L. (1996). El método arqueológico aplicado al proceso de estudio y de intervención en edificios históricos. En Arqueología de la Arquitectura (pp. 55-74). Burgos: Junta de Castilla y León.

(9) Aratikos Arqueólogos SL. (2008). Iglesia de San Miguel en Sacramenia (Segovia): Lectura de paramentos. Informe técnico inédito. Valladolid: Dirección General de Patrimonio y Bienes Culturales, Consejería de Cultura, Junta de Castilla y León.

(10) Parenti, R. (1996). Individualización de las unidades estratigráficas murarias. En Arqueología en la Arquitectura. Actas. (pp. 75-85). Burgos: Junta de Castilla y León.

(11) Caballero, L., Cámara, L. (1995). Un caso de lectura de paramentos y argumentación científica. S. Pedro el Viejo de Arlanza, Burgos-España. Informes de la Construcción, 46(435): 79-89, doi: http://dx.doi.org/10.3989/ic.1995.v46. i435.1100.

(12) Barrios, A. (1991). Despoblación y repoblación del territorio medieval segoviano. En, Congreso de Historia de la Ciudad: Actas. (pp. 1088-1988). Segovia: Junta de Castilla y León, Academia de Historia y Arte de San Quince.

(13) Departamento de Cultura de Segovia. Ficha de Yacimiento Arqueológico «San Miguel» No 40-174-0oo2-03. Junta de Castilla y León.

(14) Reyes, F. (1991). Población y sociedad en el Valle del Duero, Duratón y Riaza en la Alta Edad Media, siglos VI al XI: aspectos arqueológicos (Tesis Doctoral). Madrid: Universidad Complutense de Madrid.

(15) González-Varas, I. (2005). Conservación de bienes culturales: teoría, historia, principios y normas, Madrid: Cátedra.

\footnotetext{
${ }_{28}$ En cualquier caso, esta dualidad es bastante frecuente en los templos de este periodo, manteniendo siempre la mayor calidad técnica y los mejores materiales para las estructuras más cercanas al acceso y, por tanto, más visibles. Como sucede en la iglesia de San Vicente Mártir de Pospozuelo. En nuestro caso, esta preeminencia la recibe el lienzo meridional, atendiendo al uso de la sillería, la calidad decorativa de los vanos y la presencia de grabados.
} 